antis

TRANS · NÚM. I2 $\cdot 2008$

ARTÍCULOS · 149-168
El presente artículo estudia las traducciones al hebreo de la obra maestra de Miguel de Cervantes, Don Quijote de la Mancha. Tras la presentación de una panorámica de las adaptaciones al hebreo de dicha obra, destacando la famosa adaptación de Biálik, el estudio se centra en las dos únicas traducciones directas y completas al hebreo, la de Natán Bistritzky, de 1958, y la de Luis Landa, de 1994. Se presenta una semblanza de ambos traductores, seguida de un análisis de los rasgos generales de ambas versiones y de un seguimiento de las distintas categorías lingüísticas; se caracterizan, asimismo, las técnicas y estrategias traductoras empleadas y se realiza un examen de una serie especifica de elementos culturales. Aparte de los aspectos lingüísticos y traductores, también se presta atención a la influencia que ejercieron los sistemas de las normas en ambas versiones.

PAlabRas Clave: Quijote, Cervantes, Bistritzky, Landa, Hebreo, Traducción

\title{
El Caballero de la Triste Figura in Vesta Hebraica: un estudio descriptivo de las traducciones directas del Quijote al hebreo
}

Aharon Klaus

Universidad de Barcelona
This paper examines the Hebrew translations of Miguel de Cervantes' masterpiece Don Quijote de la Mancha. After reviewing the panorama of adaptations of this piece to Hebrew, emphasizing the famous one of Bialik, the paper shall focus on the only two direct and complete translations into Hebrew: those of Natan Bistritzky (I958) and Luis Landa (1994). A semblance of both translators will be presented, followed by a review of the general outlines of their translations, in accordance with different linguistic categories, and by a characterization of the techniques and strategies employed in the translations. Finally the translation of a series of specific elements will be underlined. Apart from linguistic and traductologist aspects, special attention would be paid to the influence of normative systems on both translations.

KEY WORDS: Quijote, Cervantes, Bistritzky, Landa, Hebrew, translation. 
I. El presente estudio tiene como objetivo examinar y comparar las traducciones al hebreo de la obra maestra de Miguel de Cervantes 150 Saavedra, El Ingenioso Hidalgo Don Quijote de la Mancha, centrándose en las versiones que cumplen con dos criterios: ser completas y ser directas del castellano. Antes de tratar con detenimiento las versiones que cumplen con estos dos requisitos, en los apartados 2 y 3 , se presenta una breve historia de las alusiones, adaptaciones, reescrituras y traducciones de Don Quijote al hebreo.

I.I ${ }^{\mathbf{I}}$ La obra maestra cervantina tiene una larga historia de alusiones, adaptaciones y reescrituras en la lengua hebrea. La primera mención de la obra en la literatura hebrea fue hecha ya en 1792 por Salomón Romanelli, uno de los pioneros del movimiento de la Haskalah [el movimiento de la Ilustración judía], en su libro «Un Viaje por Arabia» [מסע בערב] en el que describió una confrontación violenta que había sufrido en uno de sus viajes, empleando la imagen de Don Quijote y Rocinante.

Los intelectuales de la Ilustración judía del siglo XIX emparejaron simbólicamente el personaje de Don Quijote con la situación del pueblo judío, siendo como eran ambos unos marginados y estando aferrados a sus libros y a un pasado lejano. Las primeras adaptaciones del Quijote al hebreo aparecieron a finales de ese siglo y siguieron las normas de traducción de la Ilustración judía, que transformaban obras y personajes de la literatura occidental a un contexto judío, como una parte de su intento de rescatar la literatura hebrea de los límites de los textos religiosos.

I Para un análisis más detallado y amplio de las traducciones y adaptaciones del Quijote al hebreo véase el artículo de Fine (2004) en el que este apartado se basa en gran parte.
La primera de éstas es «El libro de Abinóam de Galilea o el mesías necio» [ספר אבינועם הגלילי או המשיח האוויל] de Najmán Frénkel, del año i87i, que narra las aventuras de Abinóam, una personificación de Don Quijote, convertido en un héroe judío en la Tierra de Israel a fines del período del Segundo Templo. La obra incluye algunos episodios de la obra cervantina, pero no sobrepasa el capítulo 27 del primer libro; además, es evidente que Frénkel no tradujo a partir del original castellano, sino que, probablemente, lo hizo de una traducción rusa basada a su vez en la traducción francesa, así que su obra es una reescritura incompleta e indirecta. La siguiente adaptación fue la de David Iudilevich, de I894, titulada «Don Quijote de la Mancha» [דון קישוט מן למנשה]. Se trata también de una versión incompleta e indirecta.

I.2 En cualquier caso, la adaptación más importante e influyente fue, sin la menor duda, la del considerado poeta nacional de Israel, Jaim Najmán Biálik bajo el título «Don Quijote hombre de la Mancha»; I9I2² [דון קישוט איש למנשא], cuya perspectiva ampliaremos seguidamente.

\section{I.2.I La traducción de Biálik: ¿̨una traducción o una adaptación?}

Aunque muchas generaciones calificaron esta traducción de ejemplar (Landa, 2002: 84), lo primero que se debe destacar es que la obra de Biálik es una versión muy abreviada (baste con mirar el tamaño del libro para comprobarlo), algo que el autor justifica en su prólogo por

2 La primera parte de la traducción fue publicada en I9I2 en Odesa y la segunda en I923 en Berlín; en I952, en Tel-Aviv, fue publicada por primera vez la traducción completa en un solo volumen. Las citas en el presente artículo están tomadas de esta última edición. 
el hecho de que su traducción está destinada a un público joven. Pero un análisis de la obra revela que Biálik no sólo suprimió considerables partes de la obra original sino que también transformó algunos elementos e incluso incorporó dentro de ella añadidos ausentes en el original, de manera que se puede concluir que no se trata meramente de una traducción abreviada sino de una adaptación.

\subsubsection{Transformación de elementos de la obra original}

A diferencia del mencionado caso de Frénkel, que reescribió el texto (es decir, cambió el trasfondo histórico y geográfico, además de los nombres de los personajes), en la obra de Biálik estos elementos quedan inalterados: se trata de un Don Quijote y de un Sancho Panza, además del resto de los personajes, que actúan en España en la misma época del original cervantino. Una prueba de que Biálik, al menos explícita y conscientemente, no intentó reescribir el texto se encuentra en las notas explicativas que agrega al final de su traducción (Biálik, I952: 324-326), notas que interpretan, entre otros términos, los geográficos (como «la Mancha»), los culturales (por ejemplo, «Don») y personajes históricos de la época (como el bandolero Roque Guinart) que aparecen en el original cervantino. Sin embargo, en realidad, varios elementos sí se vertieron a un contexto judío, de modo que podemos encontrar que en el texto de Biálik, por ejemplo, no otro que Sancho, que en la obra original suele jactarse de ser cristiano viejo, promete no transgredir la costumbre de la caballería que no le permite, como escudero, ayudar a su amo contra otros caballeros «así como procuro no trabajar en el día sábado» ( Biálik, I952: 50; citado por Fine, 2004). En el original se trata, naturalmente, del día domingo ${ }^{3}$.

\subsubsection{Introducción de elementos nuevos}

Además de las abreviaturas y las transformaciones, resulta que en diferentes ocasiones Biálik intercala en el texto elementos nuevos, en su mayoría religiosos, ausentes por completo en el original cervantino. Por ejemplo, en el discurso de la edad de oro de Don Quijote (Quijote I, Ir: I04-IO6) el texto de Biálik (I952: 60-62) menciona 5 veces la palabra Dios (intercalada en fragmentos de versículos bíblicos), palabra que no aparece ni una sola vez en el original de Cervantes (Landa, 2002: 88).

\section{I.2.4 Las pautas del sistema de adaptación de Biálik}

Por último, parece que el sistema de adaptación de Biálik, es decir, las abreviaturas, transformaciones y añadiduras, sigue unas pautas muy concretas, de manera que no se trata sólo de que se suprimieran «aquellos episodios que distraen al lector de lo esencial», como afirmó el poeta-traductor en su prólogo a la obra, sino que el texto de Biálik parece proyectar también su propia ideología religiosa y social.

Sírvanos de ejemplo la sistemática omisión de elementos o referencias de carácter erótico en el texto de Biálik. Un caso concreto es su traducción del famoso episodio (Quijote I, 2: 44), cuando el héroe manchego se encuentra a la puerta de la venta con dos mozas a quienes insiste en llamar «doncellas», algo que las hace reír, porque era, como explica el narrador, con

3 «Guardaré ese preceto tan bien como el día del domingo» (Quijote I, 8: 85, según la edición de Martín de Riquer, editorial Juventud (1955) I998; de ahora en adelante las citas del Quijote están tomadas de esta edición); en el apartado 3.4 veremos las traducciones de los demás traductores para esta frase de Sancho. 
claro tono irónico, «cosa tan fuera de su profesión». En el texto de Biálik (I952: 6) el protagonista se dirige a estas «doncellas» como rivot 152 [ריבות], una palabra que significa «mozas» y que no hace referencia a la virginidad. Consecuentemente, la picardía del narrador se omite por completo: en la versión de Biálik las mozas se ríen simplemente porque son «sencillas chicas del

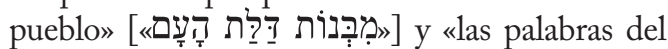

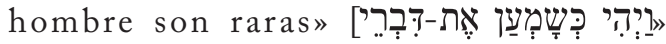

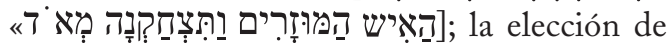
una palabra que no alude a la virginidad hace que el humor cervantino se pierda ${ }^{4}$.

A juicio de varios críticos, la traducciónadaptación de Biálik refleja también su propia percepción literaria de la obra, más concretamente, la visión romántica de la construcción del personaje protagonista y de la obra en general ${ }^{5}$.

I.2.5 La traducción de Biálik no cumple, pues, con nuestro primer criterio, de ser una traducción completa, sino que es una adaptación que suprime y transforma elementos de la obra original y también inserta elementos nuevos, todo según unos paradigmas ideológicos y literarios determinados. Esta traducción tampoco cumple con el criterio de ser una traducción directa: está ya bien establecido (Landa, 2002: 85; citando a Uriel Ofek) que Biálik no tradujo a partir del original castellano, sino de una traducción alemana y de una versión abreviada en ruso, aunque nunca lo confesó explíci-

4 Landa (2002: 88-90) analiza ampliamente cómo la traducción de Biálik refleja también su ideología social y, además, aporta más ejemplos de la omisión de las referencias de carácter erótico.

5 Landa (2002: 84), que cita como ejemplo a Lajover; Fine (2004) añade que incluso la elección estilística de Biálik del tono bíblico-profético deriva de su visión romántica del Quijote, del héroe idealista y trágico a la vez.

tamente ${ }^{6}$. No obstante, la traducción de Biálik siguió siendo la más conocida a lo largo de la mayor parte del siglo xx, y en la primera mitad de ese siglo, la única, de modo que la mayoría de los lectores hebreos de esa época conocían al héroe manchego a través de ella. Este hecho, junto con el valor literario y estético de esta traducción, escrita en un rico estilo bíblico, le otorga considerable importancia; por tanto, y a pesar de no cumplir con los criterios principales de nuestro análisis, también se hará referencia a esta adaptación ${ }^{7}$.

\section{I.3 Traducciones rigurosas del Quijote}

La siguiente versión hebrea del Quijote, del traductor Yosef Rabíkov, del año I955, parece ser la primera que puede considerarse como una traducción rigurosa y no como una adaptación. A la traducción de Rabíkov, un traductor prolífico, le fue agregado el famoso prólogo de Heinrich Heine y las ilustraciones barrocas de Doré.

Rabíkov no especifica de qué idioma tradujo, un motivo para sospechar que no fuera del castellano (porque en caso de que sí lo fuera sería lógico que lo hubiera anunciado); consolida

6 E incluso parece que intentó desdibujar este hecho cuando explicó ambiguamente, en el prólogo a su traducción, que tradujo a partir de «la nueva versión de la traducción completa de Don Quijote, encontrada en los últimos años, la cuál, a criterio de la mayor parte de los cervantistas, es la más adecuada y está exenta de pasajes o de añadidos ajenos al original» (Biálik 1952: I9; la traducción está tomada de Fine 2004).

7 Fine (2004) y Landa (2002: 97-99) opinan que también puede considerarse como reescritura del Quijote el libro «Los viajes de Binyamin III" [מסעות בנימין השלישי], de Shalom Jacob Abramovich (más conocido por su seudónimo Méndele Mojer Sfarim), escrita originalmente en yiddish y publicada en I878; Fine (ibídem) añade que en gran medida también puede considerarse como reelaboración del Quijote el libro «La escolta de la novia»] הכננסת כלה] del celebrado premio novel de literatura Shmuel Iosef Agnón (I9I9, I931 y I953). 
esta conjetura el hecho de que la mayoría de sus otras traducciones son del francés y del inglés. Sea como fuere, la traducción es incompleta: Rabíkov sólo tradujo El Quijote de r605.

La primera traducción completa e indudablemente directa del castellano es la de Natán Bistritzky, del año i958. La segunda y última traducción que es completa y directa del caste1lano, hasta el momento, es del año I994, a cargo de Beatriz y Luis Landa. El próximo apartado se dedicará a analizar con más detalle estas dos traducciones empezando por sus traductores respectivos.

\section{LOS 'QUIJOTES' HEBREOS DE BISTRITZKY Y LANDA}

Natán Bistritzky (Agmón) era crítico, dramaturgo (mayormente de piezas teatrales históricas), escritor, traductor y también un alto funcionario del Keren Kayemet Le-Yisrael ${ }^{8}$ entre I922-I952. Bistritzky, que nació en Ucrania en I896, emigró a Israel en I9I3 y murió en Jerusalén en I980, afirma que tradujo el Quijote a partir del castellano (algo que se nota mucho en su traducción y notas, como se mostrará a lo largo de nuestro estudio), lengua que llegó a dominar, posiblemente, como resultado de un viaje que había hecho por Sudamérica, después del cual publicó el libro «Impresiones de un viaje a Sudamérica - encantos de un continente»; 1948 [רשמי מסע בדרום אמריקה - קסמי יבשת].

Es preciso destacar que, lo mismo que Bistritzky, la mayoría de los traductores en el Israel de la época eran, antes que nada, autores, que veían en la traducción al hebreo una misión lingüística y cultural de la mayor importancia ${ }^{9}$.

8 Organización sionista que se ocupaba, antes del establecimiento del Estado de Israel, de comprar suelo en Palestina para colonizarlo con judíos.

9 Una panorámica de la empresa traductora de abso-
Con la labor traductora de la mayoría de las obras maestras de la literatura universal, nos atreveríamos a decir que los autores pretendían darle a la lengua hebrea una normalidad pareja a la de las demás lenguas que disponían de estas traducciones, dado que, en realidad, las versiones al hebreo no eran siempre necesarias, teniendo en cuenta que una gran parte del público lector leería con muchísima más comodidad las versiones del Quijote en otras lenguas que no fueran la hebrea ${ }^{10}$.

\section{I.I Credo traductor}

En primer lugar debería uno detenerse en el comentario que añadió Bistritzky a su traducción del Quijote, donde explica en detalle su credo lingüístico y traductor, imprescindible para comprender el carácter excepcional de su traducción, que se presentará más adelante. Dado que formula sus argumentos de una manera ambigua y compleja, intentaremos seguirlos uno por uno.

Antes que nada Bistritzky declara en este comentario la fidelidad de su traducción al original cervantino, en cuanto al ritmo, la sintaxis y el léxico, sosteniendo que «el estilo de una obra refleja su esencia». En términos de traductología, Bistritzky adopta una estrategia de traductor literal para el que la adecuación (la adhesión y fidelidad al texto de origen) se impone sobre la aceptabilidad (el respeto a las normas de la cultura y la lengua de llegada del texto ${ }^{11}$.

lutamente todos los autores hebreos desde la Ilustración y hasta, por lo menos, bien entrados los años 6o, podemos verla en: Varela, M. E. (1992). Historia de la Literatura Hebrea contemporánea, Barcelona: Octaedro.

ro Lo que nos llevaría a una de las cuestiones debatidas en traductología acerca de la diferenciación entre las versiones necesarias frente a las que cumplen una función ideológica, como es, de hecho, la traducción de Bistritzky.

II Estos términos y la mayoría de la terminología del campo de la traductología empleados en el presente artículo, se basan en Hurtado Albir (200I). 
Seguidamente, Bistritzky analiza el tipo de castellano empleado en el Quijote y lo describe como "una lengua grande y homogénea» 154 [थנה אחידה וגדולהז]; grande, según explica, en el sentido de amplia o rica; y homogénea quiere decir que incorpora elementos de todos los estratos históricos y de todos los registros de la lengua.

Luego argumenta Bistritzky que, siendo la lengua del texto original así, es imprescindible que la lengua receptora, en este caso el hebreo, participe de estas propiedades (de acuerdo con su creencia, antes mencionada, de que el estilo es la esencia de una obra) ${ }^{12}$.

Bistritzky razona, pues, su intento de traducir a un hebreo que sea grande y homogéneo, paralelo al castellano de Cervantes (lo que podríamos denominar un hebreo cervantino), primero por un motivo literario. Sin embargo, la continuación de su discurso revela que hay también otro motivo para emplear este hebreo grande y homogéneo, un motivo extra-literario y extra-lingüístico, puramente ideológico.

En las propias palabras de Bistritzky se trata de «la necesidad de salvar (a través de la creación de una lengua grande y homogénea) la frase hebrea, que está amenazada por peligro de destrucción... «; a continuación Bistritzky se expresa en términos más rigurosos aún, diciendo que la lucha para salvar la lengua hebrea es una lucha «a vida o muerte»(!) y se explica así: «la muerte significa la degeneración lingüística, que contribuye a la degeneración del alma, alma del individuo y de la sociedad, a la manera del levantinismo ${ }^{13}$, este levantinismo que amenaza

I2 Estas palabras forman una clara aunque indirecta crítica de la traducción de Biálik, que empleó en su traducción sólo el hebreo bíblico, sin incorporar elementos del hebreo rabínico.

I3 «Levantinismo» en este contexto quiere decir la preferencia cultural por lo oriental de los muchos judíos pro-

en general toda la edificación de una patria para un pueblo exiliado».

Así que Natán Bistritzky, funcionario de fuerte ideología sionista, percibe su traducción del Quijote como una misión que excede lo literario: aspira a crear una lengua hebrea paralela al español cervantino por motivos literarios, pero también con un fin ideológico: «salvar la lengua hebrea» que tiene que luchar contra el terrible peligro del «levantinismo».

Un pequeño ejemplo puede ayudar a ilustrar el carácter excepcional y ambicioso del intento de Bistritzky: a lo largo de su traducción Bis-

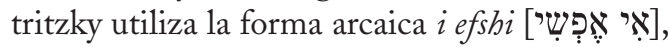
mientras que en su comentario a la traducción utiliza su paralela en hebreo moderno $i$ efshar

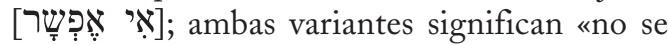
puede». Suponiendo que el comentario refleje la lengua que Bistritzky considera como más natural, se destaca que la lengua que intentó crear en su traducción, adrede y artificialmente, no es natural ni siquiera para él mismo.

\section{I.2 Resumen}

Se trata de un traductor que aboga por la fidelidad al texto original, ante todo en sus aspectos formales, es decir, adopta una actitud de traductor literal. Además, es un traductor ideológico con motivos y fines que van más allá de la literatura.

\section{2}

Luis Landa nació en Argentina en 1936 y emigró a Israel en 1954, así que se trata del primer traductor del Quijote al hebreo cuya lengua materna es el castellano. Landa es cervantista e investigador, especializado principalmente en

cedentes de países árabes e islámicos (no solo del Levante), que emigraron a Israel en esta época, preferencia despreciada por las elites israelíes de la época, en su mayoría de origen asquenazí, que favorecían la cultura occidental. 
la literatura española del Siglo de Oro y actualmente es profesor en el Departamento de Literatura Hebrea en la Universidad Ben-Gurión de Beer-Sheva. A diferencia de Bistritzky y de los demás traductores del Quijote al hebreo, Landa, como la mayoría de los traductores de nuestra época, no es un autor de ficción sino que se dedica a la crítica literaria y eligió traducir una obra que pertenece a su campo de especialización ${ }^{14}$.

\subsection{Credo traductor}

En el epílogo a su traducción (i994, vol. 2: 429) aduce Landa que intentó ser fiel al original sin dañar la diversión del lector, en la medida en que fuera posible ${ }^{15}$. En otra ocasión (una entrevista en Ha-Aretz, 13.5.2005), Landa explica su actitud traductora un poco más, diciendo que, a diferencia de Bistritzky, él no intentó conservar la sintaxis del texto cervantino, y que le importaba que la traducción hebrea fuera fácil de leer, porque así era el libro en la época de Cervantes. Landa añade que cuando traduce, intenta mantener algo que él llama el «sabor» del texto, explicando que intentar crear un paralelo exacto, aún siendo fiel al original, podría a veces vaciar el texto de este sabor. En otras palabras, Landa no cree que lo más importante en una traducción sea la fidelidad a las estructuras formales del texto original sino intentar mantener su sabor, algo que podemos calificar como estrategia de traductor libre, precisamente lo contrario de la actitud por la que aboga Bistritzky, que ve en el estilo la esencia.

\subsubsection{Resumen}

I4 Landa realizó su traducción del Quijote con su esposa, Beatriz Landau, habiendo sido el corpus de los poemas traducido por Tal Nitsan Keren.

I5 En este epílogo Landa comenta también que en su traducción se valió mucho de las traducciones anteriores, especialmente de la de Bistritzky.
Se trata de un traductor que es especialista en el campo objeto de su traducción y cuya lengua materna es el castellano. Es un traductor que cree en una traducción libre que mantenga 155 el sabor del original y que lo que más le importa es que su traducción del Quijote sea legible, de modo que al contrario que Bistritzky en la traducción de Landa se impone la aceptabilidad sobre la adecuación.

\subsection{Las traducciones}

\subsection{La traducción de Bistritzky}

La traducción hebrea de Bistritzky pone de manifiesto dos rasgos principales: el primero es la mencionada fidelidad declarada al original; el segundo, y el más destacado, es la introducción deliberada de elementos lingüísticos pertenecientes a los distintos estratos del hebreo, principalmente al hebreo rabínico, como realización de su proyecto ideológico antes explicado. A continuación se intentará revisar cómo se reflejan estos dos rasgos en la traducción, a través de una división en diferentes categorías lingüísticas, prestando especial atención a la categoría del léxico.

\subsection{I.I El ritmo, la sintaxis y el orden de las oraciones}

El ritmo y la sintaxis de la traducción de Bistritzky son muy parecidos a los del texto original: oraciones largas, con muchos signos de puntuación y muchas oraciones subordinadas, algo que es connatural al castellano pero que otorga al resultado hebreo un aspecto poco natural, dado que este idioma, por regla general, tiende a preferir oraciones coordinadas. No obstante, el hebreo rabínico se inclina más que el hebreo moderno (y mucho más que el hebreo bíblico) por las oraciones subordinadas, así que el texto de Bistritzky parece casi como un texto rabínico, en cuanto a su sintaxis (y también con 
respecto a otras categorías lingüísticas, analizadas más adelante). Además, Bistritzky tiende a conservar el orden de la oración castellana, incluso en los casos en que este orden resulte ajeno al hebreo.

Lo ejemplificaremos con una frase del principio del libro, que presentamos en la traducción de Bistritzky, seguida por el pasaje paralelo del texto original (Bistritzky, 1958, vol. I: 5; Quijote I, r: 35) y por un análisis sintácitico de la versión hebrea:

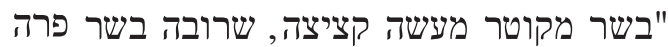

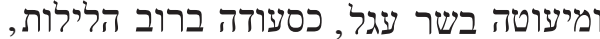
נזיר-עדשים בערבי שבתותות, קתודה ברובי-החזירותי

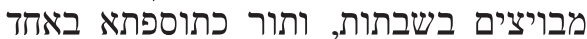
בשבת - הנה מזונותיו, שהתוריו מכלים שלושת-רבעי הכנסות אחוזתו,

«Una olla de algo más vaca que carnero, salpicón las más noches, duelos y quebrantos los sábados, lentejas los viernes, algún palomino de añadidura los domingos, consumían las tres partes de su hacienda».

Bistritzky emplea una oración larga con dos oraciones subordinadas y muchos signos de puntuación, de modo que la traducción es fiel al texto original pero es poco natural para el hebreo moderno, también por la insistencia en mantener el orden exacto del original. Es interesante hacer notar que sólo una vez en el párrafo aludido Bistritzky se permitió cambiar el orden, anteponiendo el «menú» de los viernes al de los sábados, contrariamente al orden original ${ }^{16}$.

Estos hallazgos son poco sorprendentes habida cuenta la clara afirmación de Bistritzky que intentó mantener también el ritmo y la sintaxis del original, considerando que el estilo es

I6 Cfr. 2.3.2.I, la versión de Landa de este párrafo y 3.2 acerca de la traducción de «duelos y quebrantos». algo que refleja la esencia de la obra, como ya se ha repetido. Dicho de otra manera, es un claro ejemplo de su credo como traductor literal.

\subsection{I.2 La morfología}

En la categoría de la morfología se nota que Bistritzky tiende a preferir formas arcaicas del hebreo rabínico en detrimento de las del hebreo bíblico, que son las que el hebreo moderno acabó adoptando. Con respecto a esto, los fenómenos más destacados en su traducción son:

- Las formas del esquema verbal nitpael

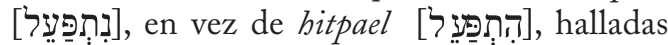
en abundancia a lo largo del texto, por ejemplo nistalek [סתלק] en vez de histalek [הסתלק]; ambas formas significan «se fue» (Bistritzky, vol. I, I958: 217).

- La conjugación de ciertos verbos a la manera del hebreo rabínico, por ejemplo, yatsta,

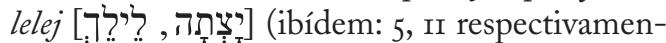
te), en vez de yatsa, lalejet [יצאה, ללכת]]; los dos pares de verbos significan «salió» $\mathrm{y}$ «andar» respectivamente.

- El sufijo rabínico del plural masculino -in [י].-], por ejemplo rujin [רוּחין en vez de rujot [רוחוחת], «fantasmas» (ibídem: Io3).

- La preferencia morfosintáctica de Bistritzky por el empleo de ein [אין para la negación de los verbos en presente en vez de 10 [לאניון], por ejemplo: en ani shomea [אין אני שומע], «no oigo» (ibídem).

Estas cuatro realizaciones, típicas del hebreo rabínico, han desaparecido casi por completo en el hebreo moderno.

\subsection{I.3 El léxico}

El léxico es el aspecto más curioso de la traducción de Bistritzky y donde se esfuerza más que en cualquier otra categoría lingüística por implementar su ambiciosa empresa de crear una nueva lengua, y por lo tanto ampliaremos 
la perspectiva acerca de ello. Bistritzky emplea consciente y deliberadamente palabras que pertenecen a distintos estratos del hebreo, la gran mayoría de las cuales son arcaísmos procedentes del hebreo rabínico que quedaron en desuso en el hebreo moderno, en algunas ocasiones alternándolas con voces naturales del hebreo moderno. Ya se ha señalado (2.I.I) el caso de la forma arcaica $i$ efshi y a continuación se aportarán unos ejemplos más.

Un caso muy revelador es la traducción de la voz escudero como sigaron [סגרגרוֹ]. Es una voz del hebreo rabínico (de origen griego) que había caído en un olvido total en el hebreo moderno, que optó por la voz nose-kelim [נושא כלים],del hebreo bíblico. Sin embargo, Bistritzky utiliza sólo la primera a lo largo de su traducción (conforme a su fin didáctico-ideológico de enriquecer el hebreo). Lo interesante es que Bistritzky se vio obligado a explicar, en su comentario a la traducción, que significa lo mismo que su homóloga bíblica-moderna:

«Sancho Panza el sigaron (es decir, nose-hakelim)»

[סנצ'ו פנסה הסגרון (לאמור, נושא-הכלים). Así que Bistritzky era completamente consciente de que la palabra que escogió era tan rara que había que «traducirla» al hebreo moderno. En este contexto, cabría destacar que la traducción del Quijote de Rabíkov, contemporáneo de Bistritzky, utiliza la variante natural para el hebreo moderno, nose-kelim, una prueba más de que esta última era la variante más connatural en la época de Bistritzky; habría que añadir que la voz castellana original «escudero» no es (ni era, en la época de Cervantes) un arcaísmo.

Otro ejemplo de la tendencia de Bistritzky hacia el léxico del hebreo rabínico es la sistemática preferencia de ilan [אילן] a su paralela moderna, de origen bíblico, ets [ץע]; ambas variantes con idéntico significado: «árbol». No obstante, el grupo léxico más destacado en la traducción de Bistritzky (que procede también del hebreo rabínico) lo constituyen los arameísmos.

La elección aleatoria de una página (la iI) de su traducción revela un número de I2 (!) arameísmos, todos asimilados en el hebreo rabínico pero de uso muy limitado en el hebreo moderno; a mi entender, este número parece reflejar bastante fielmente el promedio de los arameísmos por página en el texto entero ${ }^{17}$.

\subsection{I.4 Alternancia de voces de distintos estratos}

En varios pasajes de la traducción de Bistritzky podemos encontrar alternancia entre elementos de los distintos estratos del hebreo, por ejemplo la de los verbos amar [אמר], de origen bíblico y el más natural para el hebreo moderno, y su paralelo del hebreo rabínico, saj [סָָ] (Bistritzky, I958, vol. r: I03), ambos con el valor de: «decir».

\subsection{I.5 El registro}

A mi juicio, esta categoría lingüística (o supra-categoría, ya que engloba a todas las demás) es la más problemática en la traducción de Bistritzky. Si bien aceptamos su premisa básica, que al igual que el texto de Cervantes el hebreo empleado para traducirlo debe contener voces de todos los estratos de la lengua, Bistritzky hace caso omiso de la clara distinción de registros entre los personajes que existe en el texto cervantino (una herramienta fundamental de caracterización). Ante todo, Bistritzky no

I7 Considerando como arameísmos también las voces que no proceden del arameo pero que fueron asimiladas al hebreo rabínico a través del arameo y, por tanto, mantienen rasgos de la morfología u ortografía arameas; por ejemplo, la voz rabínica de origen latino matronit [מטרונית], «matrona», que Bistritzky emplea en su forma arameízada matronita [מטרוניתא] - con el artículo arameo $\mathcal{N}$-. 
hace patente la diferencia entre el elevado, rayano en lo ridículo, registro de Don Quijote, y el registro popular de Sancho. Bistritzky intercala elementos de registro elevado (en su mayoría arcaísmos procedentes del hebreo rabínico) a lo largo de su traducción, indistintamente del registro del hablante en el texto original, creando así un registro elevado y uniforme para todos los personajes y todas las situaciones. Así podemos encontrar en boca de no otro que Sancho, por ejemplo, muchas voces y construcciones claramente marcadas por un registro elevado en hebreo moderno.

Nos centraremos en el diálogo en el cual Don Quijote inquiere a Sancho acerca de su (supuesto) encuentro con Dulcinea (Quijote I, 3I: 3II-3I2). La imaginación de Don Quijote lo arrastra, como es habitual en él, hacia las descripciones de las damas de los libros de caballería, lo que le hace expresarse en el estilo grandilocuente de estos libros, algo que enfatiza la diferencia entre su discurso y el registro de Sancho, que insiste en describir el encuentro en términos más prosaicos y mundanos ${ }^{18}$.

Mientras que el registro elevado de Bistritzky resulta muy adecuado para reflejar el estilo grandilocuente de Don Quijote en este diálogo, este mismo registro en boca de Sancho anula la diferencia de registros del texto original. A continuación se aportan algunos ejemplos, tomados de este mismo diálogo, primero del aspecto sintáctico: en el momento en el que Don Quijote inquiere a Sancho si el trigo que estaba cribando Dulcinea cuando la encontró era «candeal o trechel», responde Sancho, lacónicamente: «no era sino rubión» (ibídem).

En su traducción, Bistritzky (1958, vol. r: 212) insiste seguir la construcción castellana

I8 Véase 2.3.2.3 para las técnicas que utiliza Landa para diferenciar los registros en este diálogo. de la oración adversativa, que refleja de nuevo su intento de mantener la sintaxis original (»לא היתה זו אלא סתם חיטה צהובה"). Esta insistencia eleva mucho el registro, ya que esta construcción en hebreo es mucho más infrecuente que en castellano. Además, así se crea una frase más larga que la del original (siete palabras frente a cuatro) y que la de la traducción que ofrece Landa (1994, vol. r: 239), de tres palabras y sin la construcción de la oración adversativa («לה צתם צהובה).

En cuanto a la categoría del léxico, abundan en boca del Sancho de Bistritzky los elementos léxicos elevados. Ante todo, se trata de palabras procedentes del hebreo rabínico, que se prefieren por las variantes más naturales en el hebreo moderno. Se aportan tres ejemplos: el verbo leayen לעיין]en lugar de likro [לקרוא] (לקוא] (1958, vol. r: 2I2) ${ }^{19}$; el verbo lehasiaj [להסיח] להיח] en vez de lomar [לומר] (ibídem: 213); o el sustantivo pat [פת] y no lejem [לחם] (ibídem).

Cabría destacar que las palabras en el original son de registro neutro («leer», «decir», «pan», respectivamente).

E1 Sancho de Bistritzky utiliza también elementos morfosintácticos que remarcan un registro elevado, por ejemplo, formas sintéticas de los pronombres afijados a los verbos,

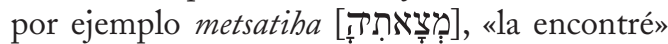
(I958, vol. I: 2I2). Las formas sintéticas de los pronombres posesivos afijados al sustantivo que utiliza Bistritzky, elevan también el registro, aunque de modo menos destacado (por ejemplo beita [הּיתֵ], «su casa»; ibídem; y cfr. 2.3.2.3, nota 23).

Para concluir, en la traducción de Bistritzky el registro de Sancho en este diálogo permanece, igual que en las demás partes del libro, sin

\footnotetext{
I9 De hecho, las palabras son de Dulcinea, repetidas por Sancho.
} 
diferenciarse del de su amo; de hecho, se trata del registro uniforme que otorga Bistritzky a todos los personajes y en todas las situaciones.

Con todo lo dicho, el fracaso de Bistritzky de reflejar fielmente los cambios de registros debería considerarse como parte de un problema más general, el de la poca experiencia y capacidad de escribir en hebreo diálogos auténticamente basados en la lengua hablada, problema que fue compartido por todos los autores y traductores de la época de Bistritzky (Ben-Shahar, 1998: 55). Cabría mencionar también que el mismo término hebreo para «registro», mishlav [מְְ̣̣] no fue acuñado hasta el año 1973 por el prestigioso lingüista Haim Rabin (Bloom, I978: I2).

\subsection{I.6 Resumen}

El ritmo y la sintaxis que emplea Bistritzky muestran su actitud de traductor literal, mientras que en las categorías de la morfología y, ante todo, del léxico, se nota de manera muy clara su empresa ideológica (ique ya podemos describir como quijotesca!), de crear un hebreo cervantino a través de la recuperación de elementos olvidados. Sin embargo, la integración artificial de elementos de los distintos estratos del hebreo, a diferencia de la integración natural en la lengua cervantina, crea una lengua poco natural y poco fluida ${ }^{20}$; ese es, a mi juicio, el pecado original de la traducción de Bistritzky.

Además, la traducción resultante sólo puede ser entendida por un lector muy culto, e incluso para un lector así, con el frecuente auxilio de diccionarios o léxicos.

La ausencia de distinción entre los diferentes registros de los personajes en la traducción de Bistritzky demuestra, a mi entender, que su empresa habría podido adecuarse más al texto

20 También a juicio de Landa (en su epílogo a la traducción, I994, vol. 2: 429) y de Fine (2004). original si se hubiera limitado a presentar los elementos arcaicos de un modo selectivo; es decir, introduciéndolos sólo para reflejar un registro elevado, manteniendo así la diferenciación intencionada de estos en el texto cervantino.

Por último, cabría señalar que aunque Bistritzky aspira incorporar en su traducción elementos de todos los estratos de la lengua, los del hebreo rabínico eclipsan a los demás, algo que, junto a la sintaxis seudorabínica, crea la impresión de que se trata de un texto rabínico y que los personajes se expresan casi como los sabios del Talmud ${ }^{21}$.

\subsubsection{La traducción de Landa}

La traducción de Landa se caracteriza, ante todo, por valerse de un hebreo moderno y fluido (a veces coloquial, pero casi nunca inclinado hacia el argot), de acuerdo con su declarado fin de que la traducción fuera legible.

También se nota su actitud de traductor libre que quiere conservar el sabor del texto original sin guardar ciega fidelidad a sus aspectos formales. Parece que estas premisas básicas dictan las técnicas lingüísticas y traductoras de Landa.

Todos estos rasgos se notan de manera muy clara en la formulación del registro de los diferentes personajes, a la cual se prestará especial atención.

\subsubsection{El ritmo, la sintaxis y el orden de las oraciones}

El ritmo, la sintaxis y el orden de las oraciones de la traducción de Landa resultan muy naturales en el hebreo moderno y no siempre dependen del texto original, según admitió el propio Landa (como se ha mencionado antes,

${ }^{21}$ Algunas de las palabras y expresiones que emplea Bistritzky no sólo son de procedencia rabínica sino también muy relacionadas con la prolija dialéctica talmúdica,

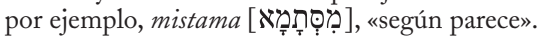


2.2.I). De ejemplo nos servirá la misma oración del principio de la obra antes examinada en la traducción de Bistritzky y comparada con el 160 original cervantino (2.3.I.I). Landa, a su vez, cambia el orden de la oración, creando una proposición nominal con hipérbaton, natural para el hebreo.

El resultado es notablemente más corto (casi la mitad) que la traducción de Bistritzky, sin ninguna oración subordinada (a diferencia de dos en el texto de este último), todo lo cual hace más natural el hebreo (Landa, I994, vol. I: 3I):

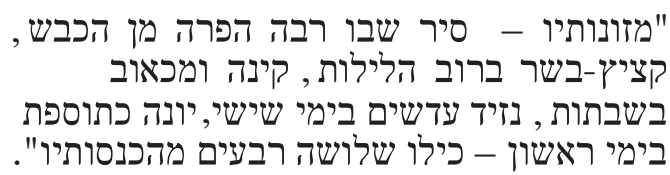

\subsubsection{La morfología y el léxico}

La morfología y el léxico que emplea Landa en su traducción son también consustanciales al hebreo moderno contemporáneo, lo mismo que la sintaxis y el orden. No obstante, es importante señalar que al igual que Bistritzky, Landa prefiere, en algunas ocasiones, variantes del hebreo rabínico en detrimento de otras variantes utilizadas por el hebreo moderno. Por otra parte, a diferencia de Bistritzky, Landa procura escoger voces que no han caído en un total olvido en el hebreo moderno, por ejemplo, la voz ilan (1994, vol. I: 47; mencionada en 2.I.3.3 acerca de la traducción de Bistritzky), y, lo que es más importante, las utiliza de manera selectiva, normalmente para reflejar un registro elevado.

Así es, por ejemplo, el empleo de la forma aramea, arcaica en hebreo moderno, shmaya

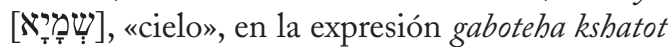

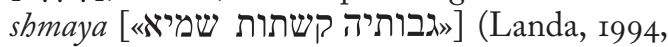
vol. I: 95). Al parecer, Landa intenta, a través de este arameísmo, remarcar el registro de Don
Quijote, que se eleva irremediablemente cuando describe a su dama, Dulcinea. Sin embargo, el elemento específico original en castellano que este arameísmo traduce no es de registro elevado ni un arcaísmo: «(sus cejas arcos del) cielo» (Quijote I, I3: I2I).

\subsubsection{El registro}

Siendo el registro, a mi entender, el aspecto más interesante de la traducción de Landa, se analizará un poco más con detalle esta supracategoría. Cabría destacar primero, que en la traducción de Landa (a diferencia de la de Bistritzky) existe una clara distinción entre los registros de los diferentes hablantes, principalmente entre Don Quijote y Sancho Panza.

Como ejemplo examinaremos el mismo diálogo entre el hidalgo y su escudero, antes analizado en la traducción de Bistritzky (2.3.I.5), ahora en la traducción de Landa (I994, vol. I: 239-240). Para destacar el registro elevado de Don Quijote Landa utiliza varias técnicas lingüísticas:

- Modismos de registro elevado: dame be-libja [דמה בלבך] y ha-shavuy be-ksameba [השבוי בקסמיה].

Cabría señalar que estos modismos corresponden a expresiones que no son de registro elevado: «haz cuenta» $\mathrm{y}$ «su cautivo caballero» (Quijote I, 3I: 3II).

- Formas morfosintácticas de registro elevado: mavtijaja [מבטיחך], «te prometo» avarjehu [אברכהו], «lo bendeciré». Las formas sintéticas, como son estos pronombres afijados a los verbos, marcan en hebreo moderno un registro elevado, a diferencia de las formas analíticas, neutras en cuanto al registro ${ }^{22}$.

- Formas léxicas elevadas: be-nijuta

\footnotetext{
${ }^{22}$ Cfr. el empleo de estas formas por Bistritzky (2.3.I.5).
} 
[בניחותא] y nabafoj bu [נהוך הוא], en detrimento de sus sinónimos neutros be-najat, lehefej, [בנחת,להפך]. La primera traduce a «despacio» en el texto original, que no es una forma elevada. El caso de nahafoj hu, que significa «por lo contrario», es más interesante aún: no traduce ningún elemento léxico del texto original, que en este punto lleva solo un signo gráfico: punto y seguido. Parece ser otro intento de remarcar el registro elevado de Don Quijote, pero más audaz que los demás, ya que en este caso el traductor libre no se basa en ninguna pieza léxica en el texto original.

Para expresar el registro popular de Sancho utiliza Landa:

- Elementos léxicos de registro popular:

klum [כלום], samti lev [מתי לביכלי לבות], yajol liheyot] יכול להיות] y yotse [יוצאיבה], en detrimento de sus homólogos de registro más elevado:

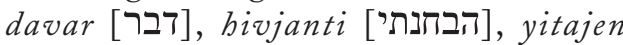
[יתכן], nodef[נודר]].

En el original cervantino (ibídem) encontramos, respectivamente: «nada», «eché de ver», «todo puede ser» $\mathrm{y}$ «sale», todos de registro neutro (y «sale» incluso se puede considerar como registro bajo: dado que se refiere a un olor, la forma correcta sería «desprende»).

- Al menos en un caso, una forma agramatical: bitkaravnu kol kaj ze la-ze [התקרבנו כל כך זה לזה], mientras que la

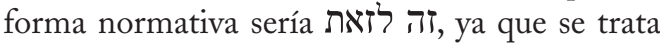
de un hombre (Sancho) y una mujer (Dulcinea) En el texto original no se trata de una forma agramatical: «llegamos tan juntos» (ibídem) ${ }^{23}$.

De los ejemplos anteriores se infiere que

23 En mi opinión, se habría podido enfatizar más aún el registro popular de Sancho en este diálogo. Por ejemplo, hubieran sido más acertadas las formas analíticas del posesivo en lugar de las formas sintéticas que emplea Landa, que en el hebreo moderno, generalmente, son marca de un registro más elevado, como se ha señalado ya.
Landa, fiel a su actitud de traductor libre, no se siente obligado a introducir los elementos que marcan el registro como bajo o elevado en las mismas ocasiones que en el texto original, sino que procura que todo el conjunto de cada discurso sea de un registro que refleje el del texto original (técnica traductora de compensación). En un caso (de nahafoj hu) hemos visto incluso la introducción de un elemento léxico elevado que no corresponde a ningún elemento léxico en el texto original.

\subsubsection{Resumen}

Los cambios en la sintaxis, el ritmo y el orden de las oraciones ponen de manifiesto una actitud de traductor libre por parte de Landa, así como su declarado propósito de que su traducción fuera legible, algo que la elección de un léxico y una morfología consustanciales al hebreo moderno refuerza. Sin embargo, Landa no duda en emplear elementos léxicos arcaicos o elevados, pero procura hacerlo de un modo selectivo, es decir, para reflejar tales elementos (o para reflejar un conjunto de discurso elevado) en el texto original.

Parece que Landa prestó especial atención al registro, y utiliza varias herramientas lingüísticas para diferenciar los registros de los distintos personajes y situaciones, como se ha ejemplificado por medio del diálogo entre Don Quijote y Sancho; es posible que éste fuera el sabor que Landa quería y logró conservar.

\section{LA TRADUCCIÓN DE ELEMENTOS Y TÉRMINOS CULTURALES, GEOGRÁFICOS, RELIGIOSOS Y MITOLÓGICOS QUE APARECEN EN EL TEXTO ORIGINAL}

3.I En este apartado quiero examinar cómo tratan las traducciones de Landa y Bistritzky (haciendo ocasionalmente referencia también 
a las de Biálik y Rabíkov) los abundantes términos y elementos culturales, geográficos, religiosos y mitológicos que aparecen en la obra cervantina, habida cuenta de que se trata de un texto de lengua y cultura alejadas del hebreo y, además, un texto anterior a la traducción en $35^{\circ}$ años (en el caso de la traducción de Bistritzky; casi 400 años en el caso de Landa), causa por la que incluso las ediciones contemporáneas del Quijote en castellano son anotadas. Se intentará presentar las traducciones de estos elementos, teniendo en cuenta también las normas predominantes en las distintas épocas de su realización.

\subsection{Términos culturales: notas marginales y otras notas}

Un rasgo muy evidente de la traducción de Landa es la abundancia de notas marginales, con el fin de llenar huecos de comprensión respecto a términos culturales que aparecen en el texto cervantino y que son ajenos a la lengua hebrea. Así es, por ejemplo, una nota que explica la referencia a la mujer de Sancho Panza, Teresa Panza, como Teresa Sancha, por la costumbre corriente de la época de aplicar a las mujeres el nombre (feminizado) del marido (Landa, I994, vol. 2: 283; Quijote I, 50: 898). En otra ocasión la nota del traductor aporta información proveniente de la crítica literaria subrayando un complejo choque de múltiples perspectivas narrativas (Landa, I994, vol. 2: I40; Quijote II, 24: 713). Otras notas explican casos de polisemia, refranes o juegos de palabras en el texto original, así que se trata de una traducción copiosamente anotada.

En muchas ocasiones Bistritzky utiliza también notas marginales para interpretar términos culturales que son, a su juicio, poco familiares para el lector israelí de su época. Por ejemplo, en una ocasión explicita una referencia indirecta a Lope de Vega (Bistritzky, I958, vol. I: 349; Quijote I, 48: 488). En otras notas Bistritzky explica juegos de palabras del texto original, por ejemplo, el doble sentido de la voz «castellano» (Bistritzky, I958, vol. I: I3; Quijote I, 2: 45).

Sin embargo, la traducción de Bistritzky es menos sistemática que la de Landa en este aspecto. Sirvan como ilustración los dos ejemplos de notas de Landa acabados de mencionar: en el texto de Bistritzky no aparece ninguna nota en los párrafos respectivos e incluso se suprime la variante distinta del nombre de la esposa de Sancho; en la traducción de Landa, por el contrario, existen las dos notas ejemplificadas acerca de Bistritzky (Landa, I994, vol. r: 37r y 38 , respectivamente).

Por añadidura, en referencia a varias expresiones ambiguas en el texto original, Bistritzky opta por una de las posibilidades sin explicitar la duda: así, por ejemplo, Bistritzky traduce la expresión «duelos y quebrantos» (mencionada en 2.3.I.I), como kotley-jazir meruyatsim [קתלי-חזיר מבויצים], «costillas de cerdo con huevos» (Bistritzky, I958, vol. I: 5), sin comunicar que esta traducción es sólo una de las interpretaciones propuestas por este enigmático par de palabras, algo que Landa dirime a través de una nota marginal (Landa, 1994, vol. I: 3I).

\subsection{Términos geográficos: las Indias}

Este término geográfico-histórico )mencionado en Quijote I, 8: 85) fue mal interpretado por la mayoría de las versiones, empezando por la de Biálik hodu [הודו], «la India» (I952: 5I, posiblemente por influencia de las traducciones mediadoras que utilizaba), pasando por la de Rabíkov ha-iyim ha-indianiyim [האיים האינדיאניים], «las islas indias» (I955: 70), y terminando con la traducción ambigua de Bistritzky artsot ha-indim [ארצות האינדים] , «los países de los hindúes / indios (?) (1958, vol. 
I: 42). Sólo en la traducción de Landa (1994, vol. I: 67) el término es correctamente interpretado: Landa lo transcribe al hebreo [לאס אינדיאס], y añade, según su modo de actuar, una nota marginal explicando que se refiere al continente de América.

\subsection{Términos religiosos: judaización del Quijote (y el eludir elementos eróticos)}

En el primer apartado (I.2.I) se ha establecido la tendencia de la adaptación-traducción de Biálik de evitar términos del mundo cristiano o traspasarlos a terminología judía. A continuación se intentará examinar las soluciones adoptadas por las demás traducciones y si muestran también tal tendencia.

Empezaremos por el tratamiento del mismo término examinado antes (I.2.2) en la traducción de Biálik, el día domingo como día de descanso. La traducción de Rabíkov (I955: 70) judaiza la frase de forma parecida a la de Biálik, convirtiendo el día domingo en día sábado. La traducción de Bistritzky (1958, vol. I: 42) opta por un compromiso interesante, evitando la mención del día domingo como día de descanso pero sin convertirlo en el día sábado, como hicieron Biálik y Rabíkov antes de él. Bistritzky traduce el día domingo como shabaton [שבתון], una voz que significa «día de descanso», pero cuyo lexema alude a shabat ${ }^{24}$.

${ }_{24}$ También en otros lugares Bistritzky opta por soluciones evasivas parecidas para evitar una mención directa al día domingo, como el empleo del término ejad be-shabat [אחד בשבת] (1958, vol. r: 5). Es un término que significa «el día domingo» pero refleja una perspectiva judía, contando los días de la semana a partir de shabat. La yuxtaposición de este último término evasivo en la misma frase con la mención precisa de la carne de cerdo (kotley jazir) refleja, evidentemente, una actitud ambivalente al respecto. Siendo su traducción indudablemente directa del castellano, tal comportamiento sólo puede ser explicado por las profundas raíces de las normas de evitar términos cristianos o no judíos, posiblemente obedecidas por los traductores sin que
Estas dos traducciones, las de Rabíkov y Bistritzky (de 1955 y I958, respectivamente), reflejan una interesante vacilación ${ }^{25}$ entre la obediencia a la antigua norma de las traducciones al hebreo, de evitar o transformar términos del mundo no judíos, como hacen los dos traductores en el último caso, y su mención directa y precisa: en otros casos de mención de términos cristianos, ambos traductores permanecen fieles al original. Se aporta como ejemplo el siguiente juramento de Don Quijote: «hago juramento... a los santos cuatro evangelios...» (Quijote I, ro: 10o). Rabíkov traduce «los cuatro evangelios» sin evitar ese término (1955: 81: ) ״, ארבעת ספרי הבשורה שבברית החדשה :..., y así también actúa Bistritzky (1958, vol. I: 51: "......... Por último, en la traducción de Biálik (I952: 57; citado por Fine 2004) Don Quijote jura aquí en nombre del Antiguo Testamento, otro claro ejemplo de judaización del texto por su parte.

Es interesante hacer notar que Rabíkov, aunque supera las ataduras de una norma de las traducciones al hebreo (la de evitar la mención de términos no judíos) permanece encadenado a otra - la de eludir o atenuar referencias de carácter sexual. A continuación del mismo juramento de Don Quijote, Rabíkov traduce «... ni con su mujer folgar» por «no acostarme en la misma cama con mi esposa»

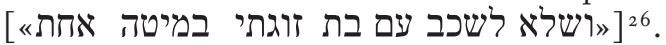
Sin embargo, esta traducción se puede considerar como progresista, comparándola con la

estos fueran completamente conscientes de ello.

${ }_{25}$ Refuerza este análisis Toury (2004: 179), que plantea que en las traducciones al hebreo se puede notar que «a partir de 1943 empieza una época de flujo entre varios sistemas de normas y una situación que está muy lejos de una decisión clara».

${ }_{26}$ Rabíkov, que tradujo todo el juramento como si fuera Don Quijote hablando en primera persona (mientras que en el original está citando al marqués de Mantua). 
traducción totalmente casta de Biálik «y no me

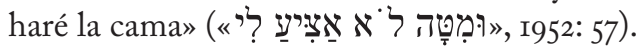

Bistritzky, a su vez, parece mantener fiel164 mente la insinuación sexual del verbo «folgar»

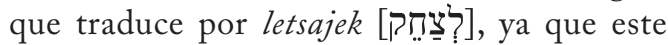
verbo tiene en hebreo un significado semejante a «folgar", de divertirse; no obstante, el verbo que escogió es poco frecuente en el hebreo moderno.

Por último, la traducción de Landa es la primera en la que ambas normas desaparecen por completo. Las menciones de los términos y elementos cristianos se traducen con precisión: el «día domingo» como yom alef ['יום $]$ y «los cuatro evangelios» como arba ba-besorot [ארבע הבשורות] (Landa I994, vol. i: 67, 79). E1 verbo «folgar» se traduce a lehitales [להתעלס], una traducción que incluso explicita el significado del acto sexual, que el verbo del texto original solo insinúa.

\subsection{Expresiones latinas (y de otras lenguas) en el texto}

E1 texto cervantino comprende ocasionalmente expresiones o refranes en latín, que las versiones de Landa y Bistritzky tratan de manera distinta.

La traducción de Landa cumple con la norma de los traductores de la época contemporánea, según la cual cualquier elemento lingüístico en el texto original que pertenezca a otro idioma debe incorporarse a la traducción en la lengua original, en muchas ocasiones con una nota marginal que lo interprete.

Presento dos ejemplos significativos, ambos del último capitulo de la obra, del testamento de Don Quijote: la primera es «item» (Quijote II, 74: 1065), que se repite cuatro veces, y la segunda es la última palabra de la obra: «vale» (ibídem: 1068). La traducción de Landa (I994, vol. 2: 4I4 y 4I6) mantiene las dos en letras latinas (dentro de su versión hebrea) y añade notas

marginales que las interpretan, explicando también que se trata de palabras latinas.

En cambio, Bistritzky (1958, vol. 2: 803) traduce vale por heye shalom [היה שלום], una formula hebrea para decir «que sigas gozando en salud». En cuanto a la repetida item, emplea dos palabras diferentes: las primeras dos apariciones se traducen por $u$-vjen [ובכן], que significa «así pues» (ibídem: 800 y 80I) y las otras dos por vejen [וכן], cuyo significado es «además» (ibídem: $803)^{27}$. Es significativo que en estos (y otros) casos la traducción de Bistritzky no aporta al lector ninguna indicación de que se trata de una palabra que es extranjera en el texto original, y así se aleja de la fidelidad que prometía mantener con respecto a éste.

En otro pasaje, cuando aparece en el texto original la expresión italiana tarde Piache (Quijote II, 53: 927) ${ }^{28}$, la versión de Bistritzky (1958, vol. 2: 69o) tampoco señala que se trata de una lengua extranjera en el texto original. Bistritzky crea una seudoexpresión hebrea rimada - sajar bimujar [שכר במאוחר], que se aleja bastante del sentido original, ya que significa «recompensa tardía». No obstante, la rima parece reflejar un intento de compensar la pérdida de la gracia de la expresión extranjera. La traducción de Landa (I994, vol. 2: 305) actúa aquí de la misma manera que en los casos de los latinismos, dejando la expresión italiana en el cuerpo del texto e interpretándola con una nota marginal.

Por último, quiero subrayar un aspecto problemático de la técnica de traducción que

${ }_{27} \mathrm{El}$ hecho de que Bistritzky optara por traducir la misma palabra de dos maneras distintas refleja otra conocida norma de los traductores, la de evitar las repeticiones del texto original. Para un análisis de esta norma véase: Ben-Ari, N. (1998). «The Ambivalent Case of Repetitions in Literary Translation». Meta, 43/I, pp. 68-78.

${ }_{28}$ Explicada por Riquer de la siguiente manera: «el que sorbió un huevo pollado, al piar el pollo en el gaznate, le dijo: «Tarde piache», o piaste.» 
adopta Landa (y de la norma conforme a la cual actúa) en los casos de palabras extranjeras. La técnica de introducir en la traducción hebrea una expresión en latín ignora la proximidad lingüística entre el castellano y el latín: una palabra latina en un texto hebreo resulta más destacada que un latinismo en un texto castellano, ya que a causa de la proximidad ortográfica, lingüística y también cultural, es de suponer que más lectores castellano-parlantes entienden su significado que lectores hebreo-parlantes.

Es posible que en algunos casos (naturalmente, no en todos), la solución adecuada sería emplear una expresión aramea, algo que, como se ha mostrado (2.3.I.3 y 2.3.2.2), Bistritzky hace con frecuencia y Landa, ocasionalmente. $\mathrm{El}$ motivo es que esta lengua mantiene con el hebreo una equidistancia semejante a la existente entre el latín y el castellano - de proximidad lingüística y también cultural. Además, $\mathrm{El}$ arameo y el latín se consideran como lenguas cultas y arcaicas que frecuentemente están empleadas en refranes (y también en el lenguaje jurídico, como es el caso de item) en el hebreo y en el castellano, respectivamente.

\subsection{Términos mitológicos: el ave Fénix y la sabia Mentironiana}

Un caso de interés es la traducción del ave Fénix en boca del Caballero de la Triste Figura, que rechaza la idea de casarse (con Dorotea), proclamando: «No es posible que yo arrostre, ni por pienso, el casarme, aunque fuese con el ave Fénix» (Quijote I, 30: 306).

Landa (I994, vol. I: 235) traduce of ha-jol [עוף החול], un nombre basado en la mención bíblica de una criatura de larga vida, jol [חול] (Libro de Job, 29, $19^{29}$ ), expresión conocida

29 El Talmud babilónico (Sanhedrín: 108) interpreta que esta mención se refiere a un ave que nunca muere. en el hebreo moderno como paralela al ave Fénix. Además, Landa añade a continuación ha-ejad ve-hayajid [האחד והיחיד], «la única», una añadidura que explica la calidad del ave Fénix al que alude la imagen (su singularidad, y no su larga vida ${ }^{30}$ ). De modo poco usual en su traducción, esta añadidura aparece en el cuerpo del texto y no en una nota marginal, aunque el texto original carece de una explícita referencia a la singularidad de esta ave.

Bistritzky traduce el ave Fénix como $h a-$

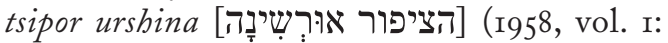
208), que según el Talmud babilónico (Sanhedrin: 108) es la paralela del hebreo rabínico a of ha-jol, o al ave Fénix. No obstante, se trata de una expresión muy poco conocida en hebreo moderno (casi tan rara como el ave misma...), de modo que marca de nuevo su traducción como destinada a un lector muy culto y muestra otra vez su determinación de revivir, no sólo palabras sino también imágenes mitológicas olvidadas. De cualquier manera, como ya se ha señalado, Don Quijote menciona el ave Fénix no por su larga vida sino por su singularidad, algo que la traducción de Bistritzky no refleja explícitamente.

Por último, interesaría mencionar que Rabíkov (I955: 256) a su vez, transforma esta imagen completamente al traducir eshet ksamim me-olam ha-agada [אשת קסמים מעולם האגדה], «Una mujer mágica del mundo legendario», de modo que la imagen original y el significado de la singularidad se pierden por completo.

Para terminar, nos ocuparemos de un término seudomitológico, de hecho más concerniente al campo del humor, el de la sabia Mentironiana, improvisada por el barbero, como parte del

30 Así lo explica también Riquer (Quijote I: 306, nota II): «se decía de ella que era la única en el mundo». 
intento de convencer al hidalgo y a su escudero para abandonar la vida de los caballeros andantes y regresar a la Mancha (Quijote I, 46: 473).

166
Landa (1994, vol. I: 359) traduce shekrona he-jajama [שקרונה החכמה], «Shekrona la sabia»; Bistritzky (1958, vol. I: 338) kzavnita hajajama [כזבניתא החכמה], «Kzavnita la sabia»; Rabíkov (1955: 392) traduce hakosemet shekroniana [הקוסמת שקרוניאנה:, «la maga Shekroniana» y añade una nota marginal — milshon sheker [מלשון שקר] —derivado de mentira».

Las soluciones de Landa y Bistritzky son bastante parecidas: las dos crean un nombre basado en una voz que significa mentira o mentirosa. No obstante, Bistritzky, según su modo de actuar, elige como base una palabra del hebreo rabínico (kazvanit), por tanto también marcada como registro más elevado, y además la arameíza, añadiendo el artículo arameo $\mathrm{k}$-, algo que eleva el resultado todavía más, como hemos señalado ya varias veces.

La traducción de Rabíkov contiene otro rasgo interesante y es que construye asimismo un nombre derivado de la palabra sheker [שקר], «mentira». No obstante, a diferencia de Landa y Bistritzky, que utilizan para derivar el nombre el sistema hebreo y arameo respectivamente, Rabíkov mantiene el sufijo español - niana añadiéndolo a la palabra hebrea; acaso sea un intento de mantener un rastro del sonido del texto original. Sin embargo, el resultado -shekroniana - es poco transparente $\mathrm{y}$, al parecer, así lo sintió el mismo Rabíkov, dado que añadió una nota marginal para aclarar su elección.

\subsection{Resumen}

En este apartado 3 se ha mostrado que es difícil concluir que la traducción de Bistritzky sea literal y la de Landa libre, como hemos planteado en el apartado anterior: en cuanto a los términos ajenos a la lengua y cultura hebreas, parece que es la traducción de Landa la que tiende a ser más literal, vertiendo con precisión los términos culturales, geográficos, religiosos y de carácter erótico del texto (mayormente a través de notas marginales) e incluso manteniendo palabras latinas en el texto hebreo. Bistritzky, por su parte, muestra una actitud más libre, transformando tales términos (como es el caso de algunos términos del mundo cristiano) frecuentemente sin indicar su origen (por ejemplo, en el caso de los duelos y quebrantos) y, como es habitual en su labor traductora, se esfuerza siempre por recuperar no sólo palabras sino también imágenes hebreas olvidadas como es el caso de ha-tsipor urshina.

\section{RESUMEN Y CONCLUSIONES}

Este estudio ha revisado las traducciones al hebreo del Quijote, principalmente las de Bistritzky y Landa desde la perspectiva lingüística así como desde la de la traductología, considerando la formación de los traductores respectivos, sus credos y las normas de traducción predominantes en cada época.

Se ha puesto de manifiesto que Landa empleó las distintas herramientas lingüísticas a fin de que su traducción fuera legible y mantuviera el sabor de la obra original, algo que se nota especialmente en la clara diferenciación entre los registros de los distintos personajes.

Bistritzky, por su parte, reclutó todo un arsenal de recursos lingüísticos para promover su empresa literaria e ideológica que consistía en crear un hebreo que integrara elementos de todos sus estratos, algo que se destaca en particular en la categoría del léxico, donde se esforzó por revivir voces olvidadas, casi todas del hebreo rabínico.

En cuanto a las estrategias traductoras res- 
pectivas, mientras que la conclusión del apartado 2, en el que se han examinado los rasgos lingüísticos de las traducciones en general, ha sido que la versión de Bistritzky tiende a ser más literal y la de Landa más libre (ambas actitudes en conformidad con sus credos declarados), el tercer apartado, que se ha ocupado de comparar la traducción de una serie específica de términos, ha revelado una situación opuesta.

Nos atreveríamos a conjeturar que este contradictorio resultado podría entenderse considerando los sistemas de normas que ejercieron su influencia en ambas traducciones, como se ha intentado mostrar en lo referente a las antiguas normas de eludir o atenuar elementos no judíos o eróticos, normas evidentes en la traducción de Bistritzky (y más en la traducción de Rabíkov); o la norma moderna de mantener siempre elementos de otras lenguas cuando son extranjeras en el original, como procura hacer Landa. Otra conclusión de nuestro estudio es que no se puede separar las estrategias lingüísticas y traductoras de la formación y perfil personal de cada traductor, como muestra, por ejemplo, la abundancia de notas marginales que agregó Landa, siendo como es un traductor especializado en el Siglo de Oro, o la empresa del traductor ideológico como es Bistritzky, empresa que debería ser examinada, a mi juicio, considerando sus motivaciones extra-literarias, nunca analizadas con detenimiento hasta el momento.

Por último, cabría mencionar que la traducción de Bistritzky ha caído en el olvido - hoy en día, para adquirir un ejemplar debe uno dirigirse a una librería de viejo - llevándose consigo su empresa quijotesca; un resultado poco sorprendente, habida cuenta de las inmensas dificultades que presenta su lectura puestas ya de manifiesto a lo largo del presente estudio.

Por el contrario, la traducción de Landa fue aceptada y difundida inmediatamente en el seno del público israelí, de manera que marcó, a juicio de Fine (2004), un redescubrimiento del Quijote por parte de los lectores israelíes e impulsó el estudio de esta obra en Israel, así como la traducción de otras obras cervantinas.

RECIBIDO EN NOVIEMBRE 2006 ACEPTADO EN MAYO 2007

\section{BIBLIOGRAFÍA}

\section{Traducciones y adaptaciones hebreas del Quijote}

דון קישוט איש לה-מנשה, תרגום מקוצר מאת ח.נ ביאליק, הוצאת "דביר", תל-אביב, 1952.

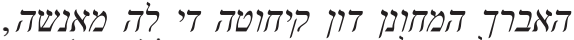

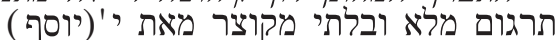
רביקוב, הוצאת "תבל", תל-אביב, 1955 (כרך א'). ההידלגו החריף דון קיחוטה מן למנצ'ת,

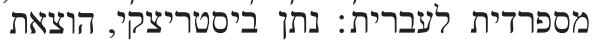
הקבוץ הארצי השומר הצעיר מרחביתיה, 1958.

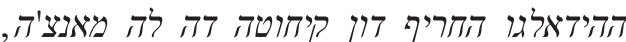

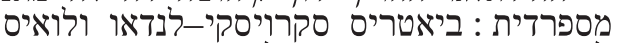

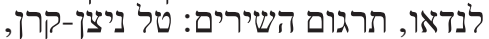
הוצאת הקיבוץ המאוחד,

\section{Bibliografía de Consulta}

Ben-Shahar, R. (1998). «The Language of Plays Translated into Hebrew from English and French - a Cultural-Stylistic Study». Meta, 43/I, pp. 54-67.

Bloom, Sh. (1978). "מקומם של ה "משלבים" בהוראת עברית למבוגרים《. Orachot Io, pp. I2-24.

Fine, R. (2004). «Aventuras y desventuras del Quijote en la lengua hebrea. Traducciones, adaptaciones y reescrituras». Actas del XII Coloquio Internacional de la Asociación Internacional de Hispanistas (José Maria Casasayas in memoriam), F. Pedraza Jiménez (ed.), Universidad de CastillaLa Mancha (en prensa). 
Hurtado Albir, A. (200I). Traducción y traductología: Introducción a la Traductología, Madrid: Cátedra.

Landa, L. (2002). סרוונטס ודיהודים [Cervantes y los Judíos»], Beer-Sheva: Ben-Gurion University of the Negev Press.

168

Parr, J. A. (2000). «Don Quixote: Translation and Interpretation». Philosophy and Literature, 24/2, pp. 387-405.
Targarona Borrás, J. (I995). Diccionario HebreoEspañol, Barcelona: Riopiedras.

Toury, G. (2004). Los Estudios Descriptivos de Traducción y más allá. Metodología de la Investigación en Estudios de Traducción, Madrid: Cátedra.

Varela, M. E. (1973). «Biálik y su versión abreviada del Quijote». Miscelánea de Estudios Árabes y Hebreos, 22, pp. 83-95. 